\title{
Management of Mild Graves' Orbitopathy
}

\author{
Mario Salvia • Nicola Curròb
}

aEndocrine Unit, Department of Medical Science, and bepartment of Ophthalmology, University of Milan, Fondazione Ospedale Maggiore Policlinico IRCCS, Milan, Italy

\section{What Is the Degree of Intra-Orbital Involvement in Mild Graves' Orbitopathy?}

Mild GO is usually diagnosed based on the assessment of soft tissue inflammation, in particular eyelid and conjunctival edema and hyperaemia, mild proptosis $(<3 \mathrm{~mm}$ above normal for race and gender) and only minor, if any, eye muscle involvement [1] (fig. 1) [see chapter by Dickinson, pp. 1-25]. In a proportion of patients, eye muscles may be significantly involved [2], although motility tests may not reveal the actual degree of inflammation unless orbital imaging is performed $[3,4]$. Orbital changes in mild GO are sometimes uniquely limited to eye muscles in the absence of soft tissue inflammation [5]. Recent work has shown that eye muscle enlargement by itself may be more significantly correlated to proptosis than retroocular fat and connective tissue hypertrophy [6].

\section{Are Mild Forms of Graves' Orbitopathy Likely to Progress to More Severe Graves' Orbitopathy?}

Progression of GO occurs during the active phase of the disease and although several studies have sought indicators for predicting response to treatment [7-13], very few of the available data have proven useful to predict progression of GO from mild to more severe forms at the first clinical examination. To date, the most reliable method of predicting potential progression of GO relies on clinical monitoring of patients by calculating at each examination the CAS and classifying severity by NOSPECS $[13,14]$. Recent work from Eckstein et al. [15] has shown that severity of GO can be predicted based on the serum levels of TRAb at 5-8 months from disease onset, but does not provide data on the number of patients with mild GO progressing to severe disease. The few data available on spontaneous progression of mild forms of GO can 

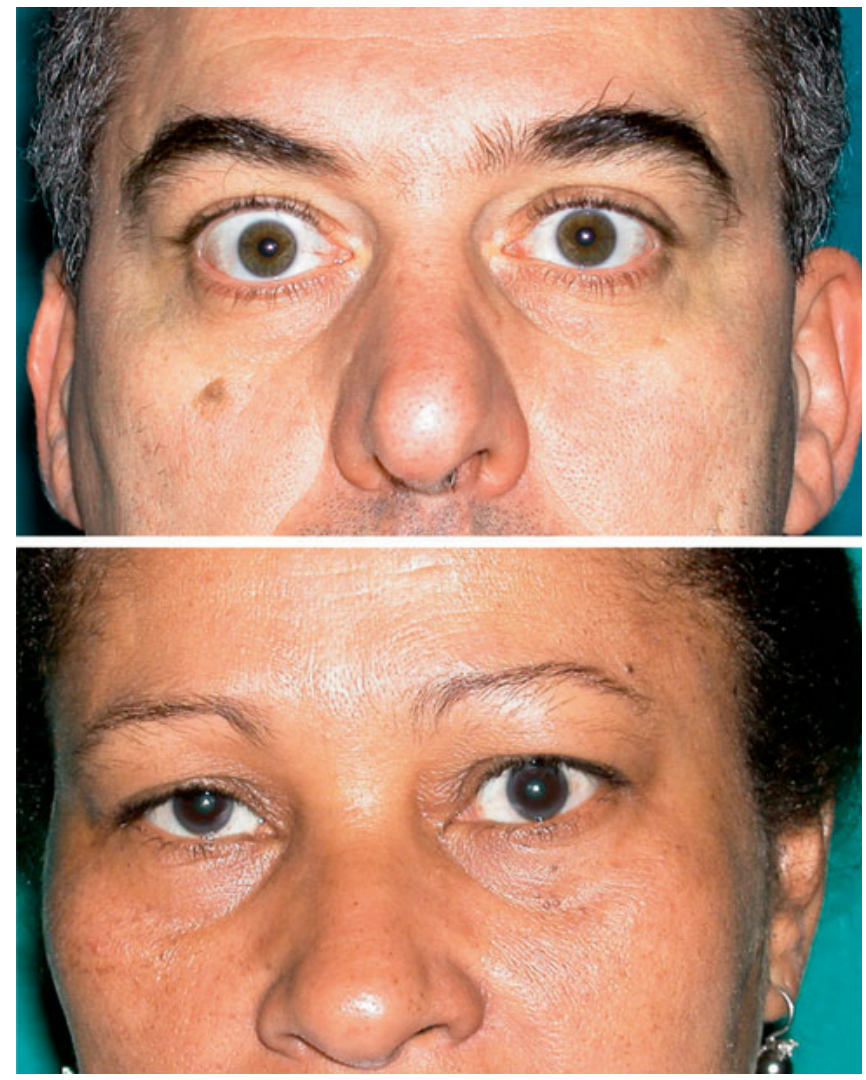

Fig. 1. Photographs of a man and a woman with active mild Graves' ophthalmopathy.

be drawn from two randomized controlled studies on the efficacy of radiotherapy, by looking at the follow-up data of the sham-irradiated control groups [16, 17]. In both these studies progression was observed in $15-16 \%$ of patients. Progression of mild GO may also occur after radioactive iodine thyroid ablation for recurrence of hyperthyroidism in a limited number of patients who are to be considered at risk because of smoking, high serum TRAb and active disease [18]. Patients with mild GO account for approximately $40 \%$ of all patients with GO seen within the multidisciplinary centres of the EUGOGO [1].

\section{Is a 'Wait and See' Policy Justified in Mild Graves' Orbitopathy?}

There are few studies addressing the issue of spontaneous evolution of GO. Perros et al. [19] have observed that up to $64 \%$ of patients with GO not subjected to therapy improved spontaneously when assessed at 3-monthly intervals. More recently, 
Table 1. Management of mild Graves' ophthalmopathy

\begin{tabular}{ll}
\hline To treat or not to treat? & \\
\hline Reasons for treating & $\begin{array}{l}\text { eye muscle involvement } \\
\text { disease progression } \\
\text { deterioration of patients' quality of life } \\
\text { chances of relevant residual orbital disease }\end{array}$ \\
\hline Reasons for not treating & $\begin{array}{l}\text { adverse effects of treatment } \\
\text { questionable efficacy on the degree of residual disease } \\
\text { spontaneous improvement } \\
\text { cost-effectiveness }\end{array}$ \\
\end{tabular}

in a slightly larger series of 81 patients treated only with local protective agents, spontaneous improvement was observed in about $47 \%$ independently of the degree of severity according to NOSPECS (classes 2-4) [20]. In the latter study, patients with mild disease who improved with no or only local therapy were $46 \%$, whereas another 51\% remained unchanged and only one worsened. In sham-irradiated control patients from randomized studies on the effect of radiotherapy, a spontaneous improvement was observed in about 30\% [16, 17]. Data from the EUGOGO centres show that about $44 \%$ patients with mild GO were indeed advised specific treatment, perhaps in relation to the reported decrease of quality of life [1] [see chapter by Wiersinga, pp. 211-220]. Reasonable arguments for treating mild GO may be based on: (1) the involvement of eye muscles, often unrecognized unless orbital imaging is performed, and solely associated to mild proptosis, as observed in some studies (see above, 'What is the degree of intra-orbital involvement in mild Graves' orbitopathy?'); (2) the chances of progression, probably very low but not clearly predictable; (3) the patient's quality of life deterioration, and (4) the physician's concern about the degree of residual disease. On the other hand, arguments for not treating may also rely on: (1) the potential side effects of either steroids or radiotherapy; (2) the outcome of therapy and its actual impact on residual disease; (3) the possibility of spontaneous disease improvement; (4) the concern about the cost-effectiveness of treatment (table 1). While 'waiting and seeing', patients can be managed with supportive measures: these are in fact effective in most patients. For instance, patients can control symptoms of dry eyes with lubricating eye drops and can obviate marked lid retraction by taping their eyes shut at night to avoid excessive irritation and corneal damage. Patients should also be advised to eliminate the modifiable risk factors, such as smoking and an uncontrolled underlying thyroid dysfunction. 


\section{Are Low-Dosage Oral Steroids Advisable or Is Orbital Irradiation Preferable?}

Both therapies have a non-specific anti-inflammatory action as well as a limited immunosuppressive effect on orbital lymphocytes. The response to steroids is typically seen in 1-2 weeks and is characterized by improvement in soft tissue signs and ocular motility. Steroids are effective at high doses and, since their use is associated with morbidity even when administered intravenously, they are generally not indicated in mild GO [21]. A low-dosage therapeutic regimen of oral prednisone has only been used with a satisfactory effect in the prevention of occurrence or progression of GO after radioactive iodine administration, although a short course of low-dose intravenous steroids might be even more effective or preferred for better compliance [22]. The therapeutic response to orbital irradiation is first seen at 2-3 weeks but a more gradual improvement is evident for several months [23]. Unless concomitant steroid treatment is used, short-term increased inflammation may initially appear as a side effect of the radiation, thereby masking the improvement in soft tissue involvement. The major advantage of orbital radiotherapy is the lack of complications. The question is if it is really effective in reducing the period of disease activity and the need for rehabilitative surgery, when the disease is burnt out. Two controlled studies have reported a significant effect of radiotherapy in GO, but were performed in patients with moderate-to-severe forms of the disease [16, 24]. Gorman et al. [25], by irradiating only one orbit and using the other one as an internal control, did not show any significant effect of therapy on the volumes of eye muscles measured by orbital CT scan in patients with mild GO. Although these negative results could have been due to the inclusion of patients with inactive disease, a proportion of whom had also been treated with steroids, that study has questioned the opportunity to treat mild GO with radiotherapy [26]. A recent randomized and controlled study by Prummel et al. [17] has shown that orbital radiotherapy is effective in mild GO, and improvement, mainly on eye motility, was observed in $52 \%$ of irradiated compared to $27 \%$ of non-irradiated patients, likely due to the effect on eye muscle infiltrating lymphocytes. They suggest that changes in the function of eye muscles may be more relevant than those of volume when one wants to assess response to treatment in GO. It is of interest that in this study control patients with mild GO, who were sham-irradiated, showed improvement, no change or worsening of disease in line with what was reported in the study on the natural history by Perros et al. [19]. Unfortunately, no conclusive answer could be given as to whether radiotherapy is better than a 'wait and see' approach in mild GO, since treatment did not improve the quality of life of patients and was not cost effective. In addition, radiotherapy did not prevent disease worsening, observed in about $15 \%$ of patients, and these data argues against an immunosuppressive effect of this treatment. 
Table 2. Adverse effects of radiotherapy in Graves' ophthalmopathy

\begin{tabular}{llll}
\hline Occurrence & Effect & Patients affected & Management \\
\hline Short term & $\begin{array}{l}\text { transient worsening of soft } \\
\text { tissue inflammation and hair } \\
\text { loss at the temples }\end{array}$ & many & possibly steroids \\
\hline Long term & cataract induction & $5 \%(>60 \text { years of age })^{*}$ & $\begin{array}{l}\text { avoid steroids, may } \\
\text { also cause cataract }\end{array}$ \\
\cline { 2 - 4 } & $\begin{array}{l}\text { definite radiation } \\
\text { retinopathy }\end{array}$ & $\begin{array}{l}0.9-2 \% \text { hypertensive, } \\
\text { diabetic patients }\end{array}$ & $\begin{array}{l}\text { avoid treating } \\
\text { diabetic patients }\end{array}$ \\
\cline { 2 - 4 } & secondary cancer & $\begin{array}{l}\text { none (median } \\
\text { follow-up 25 years) }\end{array}$ & $\begin{array}{l}\text { avoid treating patients } \\
<35 \text { years of age }\end{array}$
\end{tabular}

*From Marcocci et al. [32]: patients were also treated with steroids.

\section{Can We Reassure Patients about the Long-Term Safety of Orbital Irradiation?}

Radiotherapy is well tolerated and has almost no short-term side effects, except for an acute exacerbation of soft tissue inflammation [27]. Potential long-term complications of irradiation have been a major concern for its use in GO, particularly in milder forms. While radiation-induced tumours have not been observed in GO patients $[28,29]$, several reports of severe retinopathy have been reported, either induced by dosimetric and technique errors [30] or because of coexisting diabetes [31]. Increased cataract induction is also a concern since the lens is within the radiation beam [32]. Two recent retrospective studies have produced reassuring evidence on the long-term safety of radiotherapy in GO (table 2). Marcocci et al. [33] have studied 204 patients with moderate-to-severe GO and observed a prevalence of cataract of $10 \%$ in patients irradiated with a high voltage linear accelerator, a figure comparable to the incidence of cataract in a non-GO population of the same age. Possible radiation-induced retinopathy was detected in only 2 patients both with associated hypertension and one who also had diabetes. Wakelkamp et al. [34] conducted a follow-up study on 245 patients with moderate-to-severe GO treated with radiotherapy and found a prevalence of cataract of $29 \%$, no different from the prevalence of $34 \%$ observed in GO patients treated with steroids only. Retinal changes were seen more frequently in irradiated than non-irradiated eyes ( 21 vs. $2 \%$ ); however, these changes consisted mostly of 1-5 microaneurysms that did not interfere with visual acuity. Orbital irradiation was only associated with retinopathy in diabetic patients (relative risk $21,95 \%$ confidence interval 3-179). Diabetes mellitus is, therefore, a contraindication for orbital radiotherapy. Both these latter studies $[33,34]$ did not show 
radiation-induced tumours or increased mortality, although the duration of followup (median 11 years) may not be long enough to rule out an increased lifetime risk of cancer. From these data, it seems reasonable to reassure patients about the longterm safety of orbital radiotherapy, which can be proposed as a treatment option in patients with mild GO, with the exception of those with diabetes and hypertension or younger than 35 years of age [33].

\section{$W_{\text {hat Is the Rationale for Antioxidant Therapy in GO? }}$}

Oxygen free radicals (OFR) have been reported to be involved in the pathogenesis of GO. Studies that have linked the high prevalence of smokers to GO [35] have shown that smoking causes hypoxia within the organ tissues involved in the orbital changes of the disease [36]. OFR have been shown to be present in orbital tissues and to be involved in IL-1 $\beta$-induced glycosaminoglycans accumulation [37]. OFR also induced expression of heat-shock protein 72 in retroocular fibroblasts of patients with GO [38] and caused their proliferation, which could in part be inhibited by methimazole, allopurinol and nicotinamide [39]. Indices of OFR generation have been found to be increased in the serum of patients with GO and were normalized by corticosteroid therapy [40]. Despite this relevant experimental evidence, data on the clinical use of antioxidants in GO are limited. In a controlled non-randomized study vs. placebo, Bouzas et al. [41] were able to show a significant improvement in NOSPECS signs in patients treated with allopurinol and nicotinamide for 3 months. The improvement was satisfactory for soft tissue signs and motility, but not for proptosis reduction. Interestingly, there were no reported side effects and the patients were all smokers. This poses the question whether smokers are more susceptible to benefit from antioxidants or, alternatively, whether non-smokers would have even a greater beneficial effect from these drugs. Pentoxifylline is a cytokine-modulating drug and is also regarded as an antioxidant. Its effect on 10 patients with active moderate-to-severe GO has been examined in a pilot non-controlled study by Balazs et al. [42]. Eight patients showed soft tissue improvement, but no change in proptosis and ocular motility. More recently, a placebo-controlled, randomized study on 18 women with inactive GO showed significant proptosis reduction and improvement in quality of life in those treated with pentoxifylline compared to placebo [43]. In contrast to most pharmacological therapies aimed to control active GO, in this study pentoxifylline seems to offer an alternative to surgical treatment of inactive disease. Some interventional studies have tested the hypothesis that selenium administration may have a beneficial effect on autoimmune thyroiditis [44]. In a recent study, Wertenbruch et al. [45] found the highest serum selenium concentrations (>120 $\mu \mathrm{g} / \mathrm{l})$ in GD patients undergoing remission, indicating a positive effect of selenium levels on the outcome of Graves' hyperthyroidism. A EUGOGO multicenter randomized controlled trial has just been completed, in which patients with mild GO were randomized to take 
daily oral doses of pentoxifylline $(1,200 \mathrm{mg})$, selenium selenite $(200 \mu \mathrm{g})$ or placebo for 6 months. The results of the study were evaluated after 12 months of follow-up and presented at a recent symposium [46]. Selenium treatment induced significant improvement in $\mathrm{GO}$ in a greater number of patients than pentoxyfylline and placebo at both 6- and 12-month follow-ups. The same was true for the subjective clinical outcome measured by the GO-Qol questionnaire. Antioxidants might become an interesting option in the treatment of mild GO, perhaps in preventing progression to more severe forms.

\section{References}

1 Prummel MF, Bakker A, Wiersinga WM, Baldeschi L, Mourits M, Kendall-Taylor P, Perros P, Neoh C, Dickinson AJ, Lazarus JH, Lane CM, Heufelder AE, Kahaly GJ, Pitz S, Orgiazzi J, Hullo A, Pinchera A, Marcocci C, Sartini MS, Rocchi R, Nardi M, Krassas GE, Halkias A: Multi-center study on the characteristics and treatment strategies of patients with Graves' orbitopathy: the first European Group on Graves' Orbitopathy experience. Eur J Endocrinol 2003;148:491-495.

- 2 Mourits M, Prummel MF, Wiersinga WM, Koornneef L: Measuring eye movements in Graves' ophthalmopathy. Ophthalmology 1994;101:1341-1346.

-3 Ohnishi T, Noguchi S, Murakami N, Tajiri J, Harao M, Kawamoto H, Hoshi H, Jinnouchi S, Futami S, Nagamachi S, Watanabe K: Extraocular muscles in Graves' ophthalmopathy: usefulness of T2 relaxation time measurements. Radiology 1994;190:857862 .

-4 Ozgen A, Alp MN, Ariyurek M, Tutuncu NB, Can I, Gunalp I: Quantitative CT of the orbit in Graves' disease. Br J Radiol 1999;72:757-762.

5 Mikozami T, Salvi M, Wall JR: Eye muscle antibodies in Graves' ophthalmopathy pathogenic or secondary epiphenomenon? J Endocrinol Invest 2004; 27:221-229.

6 Kvetny J, Puhakka KB, Rohl L: Magnetic resonance imaging determination of extraocular eye muscle volume in patients with thyroid-associated ophthalmopathy and proptosis. Acta Ophthalmol Scand 2006;84:419-423.

7 Kahaly G, Schuler M, Sewell AC, Bernhard G, Beyer J, Krause U: Urinary glycosaminoglycans in Graves' ophthalmopathy. Clin Endocrinol 1990;33:35-44.

8 Hiromatsu Y, Kojima K, Ishisaka N, Tanaka K, Sato M, Nonaka K, Nishimura H, Nishida H: Role of magnetic resonance imaging in thyroid-associated ophthalmopathy: its predictive value for therapeutic outcome of immunosuppressive therapy. Thyroid 1992;2:299-305.
9 Prummel MF, Suttorp-Schulten MSA, Wiersinga WM, Verbeck AM, Mourits MP, Koornneef L: A new ultrasonographic method to detect disease activity and predict response to immunosuppressive treatment in Graves' ophthalmopathy. Ophthalmology 1993;100:556-561.

10 Gerding MN, Prummel MF, Wiersinga WM: Assessment of disease activity in Graves' ophthalmopathy by orbital ultrasonography and clinical parameters. Clin Endocrinol 2000;52:641-646.

11 Colao A, Lastoria S, Ferone D, Pivonello R, Macchia PE, Vassallo P, Bonavolontà G, Muto P, Lombardi G, Fenzi GF: Orbital scintigraphy with [ ${ }^{111}$ In-diethylenetriamine pentaacetic acid-D-phel]octreotide predicts the clinical response to corticosteroid therapy in patients with Graves' ophthalmopathy. J Clin Endocrinol Metab 1998;83: 3790-3794.

12 Krassas GE, Dumas A, Pontikedes N, Kaltsas T: Somatostatin receptor scintigraphy and octreotide treatment in patients with thyroid eye disease. Clin Endocrinol 1995;42:571-580.

3 Terwee CB, Prummel MF, Gerding MN, Kahaly GJ, Dekker FW, Wiersinga WM: Measuring disease activity to predict therapeutic outcome in Graves' ophthalmopathy. Clin Endocrinol 2005;62:145155.

14 Mourits MP, Prummel MF, Wiersinga WM, Koornneef L: Clinical activity score as a guide in the management of patients with Graves' ophthalmopathy. Clin Endocrinol 1997;47:9-14.

15 Eckstein AK, Plicht M, Hildegard L, Neuhauser M, Mann K, Lederbogen S, Heckmann C, Esser J, Morgenthaler NG: TSH-receptor autoantibodies are independent risk factors for Graves' ophthalmopathy and help to predict severity and outcome of the disease. J Clin Endocrinol Metab 2006;91:34643470 . 
16 Mourits MP, van Kempen-Hartenveld ML, Garcia MB, Koppeschaar HPF, Tick L, Terwee CB: Randomized placebo-controlled study of radiotherapy for Graves' ophthalmopathy. Lancet 2000;355: 1505-1509.

$\checkmark 17$ Prummel MF, Terwee CB, Gerding MN, Baldeschi L, Mourits MP, Blank L, Dekker FW, Wiersinga WM: A randomized controlled trial of orbital radiotherapy versus sham irradiation in patients with mild Graves' ophthalmopathy. J Clin Endocrinol Metab 2004;89:15-20.

$\checkmark 18$ Bartalena L, Marcocci C, Bogazzi F, Manetti L, Tanda ML, Dell'Unto E, Bruno-Bossio G, Nardi M, Bartolomei MP, Lepri A, Rossi G, Martino E, Pinchera A: Relation between therapy for hyperthyroidism and the course of Graves' ophthalmopathy. N Engl J Med 1998;338:73-78.

19 Perros P, Crombie AL, Kendall-Taylor P: Natural history of thyroid associated ophthalmopathy. Clin Endocrinol 1995;42:45-50.

20 Noth D, Gebauer M, Muller B, Burgi U, Diem P: Graves' ophthalmopathy: natural history and treatment outcomes. Swiss Med Wkly 2001;131:603609.

-21 Modjtahedi SP, Modjtahedi BS, Mansury AM, Selva D, Douglas RS, Goldberg RA, Leibovitch I: Pharmacological treatments for thyroid eye disease. Drugs 2006;66:1685-1700.

22 Vannucchi G, Campi I, Covelli D, Dazzi D, Currò N, Simonetta S, Ratiglia R, Beck-Peccoz P, Salvi M: Graves' orbitopathy activation after radioactive iodine therapy with and without steroid prophylaxis. J Clin Endocrinol Metab 2009;94:3381-3316.

23 Cockerham KP, Kennerdell JS: Does radiotherapy have a role in the management of thyroid orbitopathy? View 1. Br J Ophthalmol 2002;86:102-104.

-24 Prummel MF, Mourits MP, Blank L, Berghout A, Koornneef L: Randomized double-blind trial of prednisone versus radiotherapy in Graves' ophthalmopathy. Lancet 1993;342:949-954.

-25 Gorman CA, Garrity JA, Fatourechi V, Bahn RS, Petersen IA, Stafford SL, Earle JD, Forbes GS, Kline RW, Bergstralh EJ, Offord KP, Rademacher DM, Stanley NM, Bartley GB: A prospective, randomized, double-blind, placebo-controlled study of orbital radiotherapy for Graves' ophthalmopathy. Ophthalmology 2001;108:1523-1534.

26 McNab A: Does radiotherapy have a role in the management of thyroid orbitopathy? Comment. $\mathrm{Br}$ J Ophthalmol 2002;86:106-107.

-27 Bartalena L, Marcocci C, Tanda ML, Rocchi R, Mazzi B, Barbesino G, Pinchera A: Orbital radiotherapy for Graves' ophthalmopathy. Thyroid 2002; 12:245-250.
28 Marquez SD, Lum BL, McDougall IR, Katkuri S, Levin PS, MacManus PS, Donaldson SS: Long-term results of irradiation for patients with Graves' ophthalmopathy. Int J Radiat Oncol Biol Phys 2001;51: 766-774.

29 Schaefer U, Hesselmann S, Micke O, Schueller Bruns F, Palma C, Willich N: A long-term follow-up study after retro-orbital irradiation for Graves' ophthalmopathy. Int J Radiat Oncol Biol Phys 2002;52: 192-197.

30 Kinyoun JL, Kalina RE, Brower SA, Mills RP, Johnson RH: Radiation retinopathy after orbital irradiation for Graves' ophthalmopathy. Arch Ophthalmol 1984;102:1473-1476.

31 Archer DB, Amoaku WM, Gardiner TA: Radiation retinopathy: clinical, histopathological, ultrastructural and experimental correlations. Eye 1991;5:239251.

32 Beckendorf V, Maalouf T, George J-L, Bey P, Leclere J, Luporsi E: Place of radiotherapy in the treatment of Graves' orbitopathy. Int J Radiat Oncol Biol Phys 1999;43:805-815.

33 Marcocci C, Bartalena L, Rocchi R, Marinò M, Menconi F, Morabito E, Mazzi B, Mazzeo S, Sartini MS, Nardi M, Cartei F, Cionini L, Pinchera A: Longterm safety of orbital radiotherapy for Graves' ophthalmopathy. J Clin Endocrinol Metab 2003;88: 3561-3566.

34 Wakelkamp IM, Tan H, Saeed P, Schlingemann RO, Verbraak FD, Blank L, Prummel MF, Wiersinga WM: Orbital irradiation for Graves' ophthalmopathy: Is it safe? A long-term follow-up study. Ophthalmology 2004;111:1557-1562.

35 Hagg E, Asplund K: Is endocrine ophthalmopathy related to smoking? Br Med J 1987;295:634-635.

36 Shine B, Fells P, Edwards OM, Weetman AP: Association between Graves' ophthalmopathy and smoking. Lancet 1990;335:1261-1263.

37 Lu R, Wang P, Wartofsky L, Sutton BD, Zweier JL, Bahn RS, Garrity J, Burman KD: Oxygen free radicals in interleukin-1 $\beta$-induced glycosaminoglycan production by retro-ocular fibroblasts from normal subjects and Graves' ophthalmopathy patients. Thyroid 1999;9:297-303.

38 Heufelder AE, Wenzel BE, Bahn RS: Methimazole and propylthiouracil inhibit the oxygen free radicalinduced expression of a 72 kilodalton heat shock protein in Graves' retroocular fibroblasts. J Clin Endocrinol Metab 1992;73:307-313.

39 Burch HB, Lahiri S, Bahn RS, Barnes S: Superoxide radical production stimulates retroocular fibroblast proliferation in Graves' ophthalmopathy. Exp Eye Res 1997;65:311-316. 
40 Bednarek J, Wysocki H, Sowinski J: Peripheral parameters of oxidative stress in patients with infiltrative Graves' ophthalmopathy treated with corticosteroids. Immunol Lett 2004;93:227-232.

41 Bouzas EA, Karadimas P, Mastorakos G, Koutras DA: Antioxidant agents in the treatment of Graves' ophthalmopathy. Am J Ophthalmol 2000;129:618622.

42 Balasz C, Kiss E, Vamos A, Molnar I, Farid NR: Beneficial effect of pentoxifylline on thyroid associated ophthalmopathy (TAO): a pilot study. J Clin Endocrinol Metab 1997;82:1999-2002.

- 43 Finamor FE, Martins JRM, Nakanami D, Paiva ER, Manso PG, Furlanetto RP: Pentoxifylline (PTX) An alternative treatment in Graves' ophthalmopathy (inactive phase): assessment by a disease specific quality of life questionnaire and by exophthalmometry in a prospective randomized trial. Eur J Ophthalmol 2004;14:277-283.
44 Negro R: Selenium and thyroid autoimmunity. Biologics 2008;2:265-273.

45 Wertenbruch T, Willenberg HS, Sagert C, Nguyen TB, Bahlo M, Feldkamp J, Groeger C, Hermsen D, Scherbaum WA, Schott M: Serum selenium levels in patients with remission and relapse of Graves' disease. Med Chem 2007;3:281-284.

46 Marcocci C, Altea M, Kahaly G, Pitz S, Krassas G, Boboridis K, Bartalena L, Sivelli P, von Arx G, Stahl M, Nardi M, Mourits M, Baldeschi L, Pinchera A, Wiersinga W, on behalf of EUGOGO: Placebocontrolled trial of pentoxiphyllin vs selenium in mild Graves' ophthalmopathy. Int Symp Graves' Orbitopathy, Amsterdam, October 29-30th, 2009. 